\title{
Etapas de la distribución-exhibición cinematográfica en Uruguay (1895-2000)
}

\author{
Stages of cinematographic distribution-exhibition \\ in Uruguay (1895-2000)
}

\section{Santiago González Dambrauskas*}

\footnotetext{
* Magíster en Información y Comunicación y licenciado en Ciencias de la Comunicación por la Universidad de la República de Uruguay (Udelar). Docente de la Facultad de Información y Comunicación (FIC-Udelar) y de la Facultad de Arquitectura, Diseño y Urbanismo (FADU-Udelar). Integrante del Laboratorio Audiovisual de Contenidos (LAC) y del grupo de investigación Ambigrama (FIC-Udelar). $\triangle$ santiago.gonzalez@fic.edu.uy https://orcid.org/0000-0002-

7201-3121
}

\section{RECIBID 0: 10.3.2021}

ACEPTADO: 5.4 .2021

\section{Resumen}

El trabajo indaga en el desarrollo de la distribución-exhibición cinematográfica y propone una periodización histórica para el caso uruguayo. La primera parte del artículo introduce el tema. Luego, a partir de revisión bibliográfica y documental, se identifican cuatro grandes etapas en Uruguay durante un lapso que abarca más de un siglo (1895-2000). El artículo marca hitos y describe brevemente cada una de las etapas identificadas: primitiva (1895-1920), industrial (1930-1955), de divergencia (1955-1980) y de reestructuración (19802000).

Palabras clave: cine, historia del cine, Uruguay.

\section{Abstract}

This article investigates the changes processed in the film distribution and exhibition sector and proposes a historical periodization for the Uruguayan case. The first part of the article introduces the topic. Then, based on a bibliographic and documentary review, four major stages in the development of film distribution and exhibition in Uruguay are identified, covering more than a century time span (1895-2000). The article marks milestones and briefly describes each of the identified stages: primitive (1985-1920), industrial (1930-1955), divergent (1955-1980) and restructuring (1980-2000). Keywords: cinema, history of cinema, Uruguay. 


\section{Introducción}

Uno de los cambios más visibles que trajo el siglo XXI para el cine, mediante la introducción de las denominadas nuevas tecnologías, se encuentra ligado a su capacidad de difusión. Ya no es necesario ir a una sala cinematográfica para ver una película; podemos hacerlo incluso desde un teléfono celular.

El presente artículo indaga en los antecedentes de este fenómeno, realizando un recorrido panorámico por el desarrollo de la distribución-exhibición cinematográfica desde sus inicios hasta fines del siglo XX. Para ello, y entendiendo las limitaciones y simplificaciones que cualquier generalización implica, se partirá de la tesis de Lipovetsky y Serroy (2009) de que la historia del cine puede dividirse en cuatro grandes etapas en las que el cine revolucionó sus principios.

La primera fase identificada por los autores corresponde a los inicios y la posterior época, denominada cine mudo. Es el momento en que el cine «busca para sí una condición y una definición artística» (p. 17) y puede caracterizarse como una etapa primitiva del negocio. La segunda fase, conocida como clásica (y que aquí se denominará industrial), va desde comienzos de la década del treinta hasta la del cincuenta. Es el momento en que se consolida Hollywood (tanto en el plano artístico como económico) a partir de un sistema bastante estructurado de producción, distribución y exhibición que se profundiza con la llegada del denominado cine sonoro.

La tercera fase discurre entre las décadas del cincuenta y setenta, y en el plano estético-expresivo se caracteriza por la emergencia de distintas vanguardias cinematográficas: la nouvelle vague francesa, el free cinema inglés o el cinema novo brasileño, por mencionar algunos ejemplos externos a Hollywood que aportan una liberación estilística, narrativa y temática que se aleja de los principios del cine clásico norteamericano. Paralelamente, se marca un hito que revoluciona la industria: la llegada de la televisión. Hay que tener en cuenta que hasta ese momento (mediados del siglo pasado) la exhibición en salas era el único medio de consumo de productos cinematográficos.

La cuarta fase se inicia en la década del ochenta, persiste en la actualidad y, en rigor, es el núcleo del estudio. En lo que respecta al fenómeno de distribución-exhibición se da un progresivo cambio en la modalidad de consumo, vinculado al desarrollo de nuevas tecnologías (video, televisión por cable y satelital, internet, teléfono móvil) que llevan de una recepción colectiva del fenómeno (salas de cine) hacia una más individual, inserta en los espacios domésticos.

En este trabajo, a partir de revisión bibliográfica y documental, se identifican y adaptan estas etapas al contexto uruguayo, haciendo foco en el desarrollo de la exhibición-distribución cinematográfica del país en un período que va desde fines del siglo XIX hasta fines del siglo XX. La delimitación temporal es aproximada; podrían incluirse fechas específicas para marcar el pasaje de una etapa a la siguiente; por ejemplo: 1896 
(primera exhibición), 1929 (proyección de primer film sonoro), 1956 (primera transmisión televisiva). Del mismo modo, como el trabajo aborda el caso nacional contextualizándolo con lo que ocurría a escala global, se hace necesario mencionar que los acontecimientos que marcaron hitos no ocurrieron en paralelo, sino que existió un desfase que en algunos casos se expresó en décadas. A modo de ejemplo, la televisión ya se encontraba en auge en Estados Unidos en la década del cincuenta, y en Uruguay el fenómeno comenzó a delimitarse en los años sesenta. Lo mismo ocurre con otros hitos que serán abordados, como la llegada del video, la experiencia de la televisión por abonados o las salas múltiples de exhibición. En este sentido, el artículo se limita a identificar y describir grandes etapas que habiliten la profundización o el detalle en futuros trabajos sobre el tema.

\section{Etapa primitiva: del cinematógrafo a las sallas (1895-1920)}

El 28 de diciembre de 1895 es la fecha que suele tomarse para delimitar el nacimiento del cine, por tratarse de la jornada en que los hermanos Lumière presentaron sus cortometrajes en París. La propia palabra cine (cinema) no es más que un acortamiento del invento de los Lumière: el cinematógrafo (cinématographe). El cinematógrafo no fue el único invento destinado a registrar imágenes en movimiento, pero en gran medida se consolidó debido a su practicidad para el registro y a la posibilidad de convertirlo en un proyector (Barnow, 2005). No es menor el hecho de que el cine no nació con el registro, sino cuando se produjo el contacto de ese registro con el público.

En Uruguay, Sanjurjo Toucon (2021) asegura que ese contacto sucedió por primera vez en el Salón Rouge de Montevideo el 18 de julio de 1896, solo seis meses después de que ocurriera en Francia. A partir de entonces las exhibiciones comenzaron a expandirse como espectáculos de entretenimiento, con proyecciones de cortometrajes que llegaron a Uruguay en carácter de novedad, pero sin una estructura de negocio planificada más que la de explotar la curiosidad de los interesados. Léase, a modo de ejemplo, el siguiente fragmento de un diario de la época, donde se hace referencia a las proyecciones de algunas de las obras más famosas de los Lumière:

En la calle 25 de Mayo, en los bajos de la casa de la familia Regalía, ha llamado la atención en estas noches pasadas un saloncito todo tapizado de rojo, alfombrado por dos o tres lámparas y adornado con algunas plantas. [...] Después del salón rojo, el espectador pasa a otro salón completamente a oscuras, donde solo se ve una gran pantalla blanca. [...] En el fondo resalta sobre una pared negra con tres agujeros [...]. Pero de estas vistas, una de las que más llama la atención es la llegada 
de un tren. Se ve avanzar la locomotora y el convoy. Se para el tren, se abren las portezuelas, los pasajeros bajan al andén, los empleados corren, se buscan los amigos... Todo esto aparece con un movimiento tan natural que el espectador queda maravillado. La salida de los operarios de una fábrica es también vista admirablemente. Se abre la puerta y un tropel de mujeres sale apresuradamente en todas direcciones. Algunos ciclistas pasan de carrera; sale un coche a todo escape, un carro más atrás. Se ven también escenas callejeras, un baile al son de un organillo... La concurrencia que asiste a las sesiones del Cinematógrafo es numerosa. Todos salen de allí maravillados. El aparato funciona desde las siete hasta las diez de la noche. (Sanjurjo Toucon, 2021, s. p.)

Diez años más tarde, en 1907, Roberto Natalini y Domingo Deste (Natalini y Cía.) iniciaron el negocio de la distribución de filmes en el Ideal, situado en la plaza Independencia (Ministerio de Industrias y Trabajo [MIT], 1955). De acuerdo a Remedi (2001; 2003), aquellos primeros espectáculos de cinematógrafo tuvieron lugar en teatros o en los denominados biógrafos, creados para tales fines (Edison Salón, Edén Park, Varietè Cinema, Biógrafo Lumière, entre otros). Hacia 1910 Montevideo contaba con 30 salas, en 1920 la cantidad era de 63 y en 1930 llegaba a 80. La mayoría exhibía películas de cine mudo, en blanco y negro, por lo general acompañadas de música en vivo.

En un plano general, se trató de un período primitivo del negocio. Hollywood prácticamente no existía y las proyecciones se realizaban en ambientes poco propicios, lugares modestos y de escasas pretensiones; luego se fueron desarrollando espacios propios de difusión, que empezaron a emerger en los centros urbanos a medida que el negocio crecía. Habría que esperar hasta la década del veinte (guerra mundial mediante), pero particularmente a la de los años treinta, para confirmar la consolidación del cine como entretenimiento de masas, teniendo a Estados Unidos como principal actor dentro del mercado.

\section{Etapa industrial: Glüicksman y la época de oro (1930-1955)}

A comienzos de los años veinte, en las más importantes ciudades de Occidente, se confirmaba el crecimiento del cine (tanto en el plano artístico como en el económico) y comenzaban a aparecer las primeras salas exclusivas de exhibición cinematográfica. En Uruguay este proceso empezó en 1927 con la aparición del Rex Theatre, el Olimpia, el París, el Azul, el Buckingham y el Mogador. Era el momento en que se consolidaba Hollywood y, de su mano, el cine como forma principal de entretenimiento (ocio popular 
por excelencia), a partir de un sistema bastante estructurado de producción, distribución y exhibición.

En la década del treinta (con la llegada del cine sonoro), luego de un breve período de transición tecnológica e incertidumbre, el fenómeno se consolidó desde Estados Unidos. En términos de lenguaje cinematográfico, se perfeccionó un sistema narrativo continuo (claro y fluido) que en nuestros días se conoce como cine clásico norteamericano y que predominó en las narrativas cinematográficas del siglo XX (Bordwell et al., 1997). Desde el punto de vista comercial, la denominada época de oro del cine de Hollywood (1930-1960) conformó una estructura en cadena con una base clara en un sistema de grandes estudios de producción y una distribución internacional de sus producciones.

En Montevideo, las primeras proyecciones de cine sonoro datan de 1929, cuando el Rex proyectó la primera película de este tipo. Como se puede apreciar, la denominada época de oro tuvo eco, como en el resto del mundo, también en Uruguay. En este caso, la consolidación y expansión del negocio llegó de la mano de la empresa Glücksmann (firma familiar austríaco-judía) que desembarcó en Buenos Aires a fines del siglo XIX y ya en los primeros años del XX tenía emprendimientos comerciales de distribución y exhibición en Chile, Perú y Uruguay. En Uruguay se instaló el menor de la familia (Bernardo), quien comenzó el emprendimiento a inicios de la década del diez y ya a finales del veinte había logrado copar la plaza. Su modelo de negocios se dirigió a obtener material de exhibición en exclusividad por medio de costosos contratos y luego hacer pesar esa condición en el mercado. El Programa Glücksmann contaba, de esta forma, con el estreno de los estudios más importantes: Metro Goldwyn Meyer, Artistas Unidos, First National, Fox, Universal y Columbia (Saratsola, 2005).

Además de la firma Glücksman, existieron en el período varios distribuidores y exhibidores locales, como CENSA (Compañía Exhibidora Nacional S.A.), SAUDEC (Sociedad Anónima Uruguaya de Exhibidores Cinematográficos) y CCC (Compañía Central Cinematográfica S.A.). En este contexto, las redes de exhibición con aspiraciones debían tener al menos un local de gran porte. Glücksmann contaba con cuatro: Radio City (1937), Trocadero (1941), Coventry (1943) y Eliseo (1949), con entre 1000 y 1300 butacas cada uno. Pero la competencia tampoco se quedó atrás y llegó a utilizar enormes salas unitarias: CCC el Cine Plaza (1950), CENSA el Censa (1953) y SAUDEC el 18 de Julio (1959) (Saratsola, 2005).

Finalmente, el auge (y la posterior decadencia) de la firma Glücksman y sus competidores en Uruguay fue acompañando los cambios que se iban procesando en el sistema de distribución-exhibición internacional. En primer lugar, varios sellos extranjeros (Paramount, Warner Bros., 20th Century Fox, Metro Goldwyn Mayer) se instalaron en América Latina para explotar su producción directamente y no a través de intermediarios (como era el caso de Glücksman). Aunque en Uruguay este hecho no fue tan vi- 
sible en las salas de exhibición, ya que, salvo el caso del Metro (de Metro Goldwyn Mayer), en su gran mayoría las salas continuaron en manos locales, sí se produjo el fenómeno dentro de la distribución. La firma Glücksman, por ejemplo, pasó de controlar la exclusividad de distribución de los sellos más importantes y casi el 50\% de la distribución cinematográfica local en 1932 a menos del 1\% en 1962 (Saratsola, 2005).

Por otro lado, la llegada y la posterior popularización de la televisión desde mediados de la década del cincuenta generó una profunda crisis en Hollywood y su negocio, entre otros factores, por la progresiva disminución de espectadores que se fue produciendo en las salas cinematográficas (Gubern, 2016; Márquez, 2015). Algunos datos de Montevideo representados en el siguiente cuadro, demuestran, no obstante, el extraordinario éxito del negocio durante el período:

Cuadro 1. Evolución del número de habitantes, salas cinematográficas y espectadores. Montevideo, 1933-1953

\begin{tabular}{|l|c|c|c|}
\hline Año & Población & Número de salas & Cantidad total de espectadores \\
\hline 1933 & 500.877 & 69 & 3.145 .582 \\
\hline 1943 & 714.039 & 77 & 8.186 .151 \\
\hline 1953 & 826.405 & 105 & 19.152 .019 \\
\hline
\end{tabular}

Fuente: Elaboración propia a partir de MIT (1955), Saratsola (2005) y Observatorio Montevideo (s.f.).

\section{Etapa de divergencia: televisión y otros circuitos (1955-1980)}

\section{Televisión}

Hasta la llegada de la televisión, la única manera de acceder a las películas era mediante su exhibición (proyección) en salas, ya fueran estas comerciales, de arte y ensayo o de muestras y festivales. La innovación de la televisión, su producción masiva y la rápida generalización de la televisión abierta establecieron un paradigma contradictorio en el fenómeno de la distribución que puso en crisis la estructura desarrollada durante la época de oro. Por un lado, planteaba una nueva posibilidad de explotación, pero, al mismo tiempo, ponía en jaque el esquema clásico de explotación mediante salas de estreno comercial, que perdían público.

A modo de ejemplo, en Estados Unidos la asistencia semanal a las salas se redujo de 90 millones de espectadores en 1946 a 16 millones en 1971 (Romaguera y Alsina 
Thevenet, 1993; Barbáchano, 1973). Paralelamente, en 1945 solo 8 millones de hogares contaban con televisión, diez años después eran 35 millones (67\% de la población) y a finales de la década del sesenta el porcentaje se ubicaba en el 95\% (Márquez, 2015). A Uruguay la televisión llegó sobre fines de los cincuenta e inicios de los sesenta. El primer canal en emitir fue Canal 10 (1956), al que le siguieron Canal 4 (1961) y Canal 12 (1962). A pesar de ser proyectado antes que los canales privados, Canal 5 (Sodre) fue el último en salir al aire (1963). Este proceso fue acompañado de una pérdida de espectadores en las salas cinematográficas. De acuerdo a datos de Saratsola (2005), en 1960 la asistencia fue de casi 18 millones y, tras un proceso continuo de baja durante la década, llegó a poco más de 8 millones en 1970.

Si bien no se puede afirmar que la llegada de la televisión sea el único factor que explique el descenso del número de espectadores para el caso uruguayo, ${ }^{1}$ es indudable que, tanto en el ámbito local como internacional, su llegada llevó a una progresiva transformación del sistema de distribución-exhibición cinematográfica y a un cambio dentro de la estructura del negocio. En otras palabras, hasta ese momento toda la estructura de producción, distribución y exhibición cinematográfica se basaba en el principio de que la recaudación se daba en salas.

Este fenómeno de divergencia del mercado hizo que las enormes salas desplegadas en todo el mundo (verdaderos palacios cinematográficos) redujeran sus ingresos y, por consiguiente, comenzaran un proceso global de decadencia. Por su parte, Hollywood, como respuesta al fenómeno, optó por diversas estrategias (innovación tecnológica incluida) para recuperar a sus espectadores en un momento de crisis. La más clara consistió en intentar separar el cine de la televisión, transformando al primero en un verdadero espectáculo sensorial. Además de extender el uso del color (la televisión era en blanco y negro), realizó grandes superproducciones, ensanchó drásticamente las pantallas, intentó introducir el denominado 3D y desarrolló un protagonismo aún mayor del sonido, por solo nombrar algunos ejemplos (Márquez, 2015; Gubern, 2016).

\section{Cineclubes}

Por fuera de los circuitos de exhibición tradicional (salas comerciales), es necesario mencionar los movimientos cineclubistas, que en Uruguay tuvieron su auge entre las décadas del cincuenta y el sesenta. Los fundamentos de esta actividad, que de alguna

1 Hay que tener en cuenta que a mediados de la década del cincuenta Uruguay comenzó un largo proceso de crisis económica. Esta iría decantando en una fractura política y social que desencadenaría el golpe de Estado de 1973 (véase Caetano y Rilla, 2001). 
manera es la contracara de los circuitos de exhibición comercial, consisten en dar a conocer un cine diferente al de los circuitos regulares, realizar ciclos o muestras especiales, editar boletines o generar bibliotecas sobre la especialidad con el fin de formar y acercar otra forma de cine a los espectadores.

Las instituciones más importantes del período fueron el Cine Universitario del Uruguay y Cine Club del Uruguay, que rivalizaron y desplegaron una intensa actividad. Además de la exhibición, ofrecían publicaciones, cursos, conferencias e incluso realizaron experiencias de producción de cortometrajes. De ambos cineclubes, además, surgieron cinematecas que terminaron por fusionarse cuando se creó Cinemateca Uruguaya (1952), que luego se independizó, tuvo varias etapas y continúa en la actualidad (Sanjurjo Toucon, 1994; De los Santos Marauda, 1992; Remedi, 2003).

Por otro lado, se debería añadir la intensa actividad del departamento de Cine Arte del Sodre, que a partir de 1954 organizó una serie de importantes festivales y muestras, entre las que se destaca el Festival Internacional de Cine Documental y Experimental (de ocho ediciones). Esta actividad alentó la producción nacional de cortometrajes y se situó como un espacio de encuentro para el cine documental internacional y latinoamericano, al posibilitar la visita de importantes realizadores y el descubrimiento de un cine hasta el momento poco conocido en el país (Amieva, 2018).

Finalmente, una mención particular merece la C3M (Cinemateca del Tercer Mundo), por lo corto de su experiencia (1969-1974) y lo singular de sus características. Como derivación de exhibiciones aisladas organizadas por el semanario Marcha, la C3M promovió exhibiciones de fuerte contenido ideológico y militante, en contextos tan diversos como fábricas ocupadas, sindicatos y comités de base. Entre sus objetivos se encontraban recopilar, archivar y divulgar películas consideradas políticas, en el entendido de que el cine debía utilizarse como un arma para intervenir en la sociedad y en el destino de la nación (Jacob, 1997; Villaça, 2012). En este sentido, su obra más importante fue la producción propia de una filmografía que instaló a la cinematografía uruguaya en el contexto regional en el marco del Nuevo Cine Latinoamericano (Dufuur, 2018), en un contexto político, económico y social convulsionado que decantaría en un largo período de dictadura cívico-militar.

\section{El nuevo Uruguay}

El período dictatorial merecería un espacio aparte, por lo extenso (1973-1984) y por los cambios indudables que se dieron no solo en el sector audiovisual uruguayo, sino, obviamente, en la sociedad. Intentando resumir lo que aquí se analiza, se podrían destacar algunos aspectos. 
El número de espectadores continuó su descenso: de más de 8 millones en Montevideo en 1970 pasó a poco más de 4 millones en 1984, si bien con variaciones durante el proceso, con un promedio de más de 5 millones anuales en una población menor al millón y medio de habitantes (Saratsola, 2005).

Por otro lado, en alguna medida Cinemateca Uruguaya terminó por sustituir el rol de los tradicionales cineclubes, que en su gran mayoría desaparecieron, lo que la llevó a vivir un momento de esplendor. En ese sentido, Sanjurjo Toucon (1994) resume las consecuencias del golpe de Estado para los cineclubes en los siguientes puntos: a) la desaparición de la C3M y del Cine Club de Marcha, b) la expropiación de la sede de Cine Club y su posterior desaparición, c) las prohibiciones de films en exhibiciones culturales y comerciales y d) el impedimento a algunas personas para ejercer cargos en las instituciones culturales en que venían trabajando. Además, Cine Arte del SODRE había sufrido un enorme incendio (1971) que prácticamente la hizo desaparecer.

Por último, habría que destacar que en 1975 se creó la Dirección Nacional de Relaciones Públicas (DINARP), con dos funciones: por un lado, producía información que luego distribuía a través de los medios tradicionales y, por el otro, oficiaba de organismo censor sobre los medios y sus contenidos. De acuerdo a Marchesi (2001), la dictadura intentó imponer en los ciudadanos sus propios valores y principios, con una actitud paternalista. Creían estar creando un nuevo Uruguay, al que buscaban identificar con nuevas representaciones y prácticas.

\section{Etapa de reestructuración: salas, video y televisión (1980-2000)}

\section{Cambios en el consumo y decadencia de los palacios de cine}

En 1990 el 85\% de los hogares disponía al menos de un televisor, con un promedio de exposición de entre dos horas y media y tres horas diarias, mientras que un cuarto de la población le dedicaba cinco horas o más (Stolovich et al., 1997). En el mismo período apareció el videocasete (clubes de video incluidos) y luego llegó la televisión cable (mediante sistema de abonados), lo que permitió diversificar la oferta televisiva. De esta forma, en la etapa posdictadura, el espacio doméstico comenzó a legitimarse como escenario privilegiado de consumo audiovisual de los uruguayos (Radakovich, 2011).

A su vez, el número de espectadores tuvo un momento crítico durante los años ochenta e inicios de los noventa, y solo a fines del siglo XX comenzó a repuntar. Es importante aclarar que cuando se habla de disminución del número de espectadores solo se hace referencia a las salas cinematográficas, ya que en los hechos el cine se veía cada 
vez más, pero en otras pantallas. El descenso fue continuo desde 1980, con cifras similares a las de la década anterior (más de 5 millones), hasta 1994, con menos de un millón de espectadores (Observatorio de Montevideo, s.f.).

Por otro lado, el eslabón no hogareño de la distribución cinematográfica (salas) era cada vez menos importante en términos económicos. En Estados Unidos, por ejemplo, los ingresos a los distribuidores provenientes de la recaudación de las salas eran el $76 \%$ en 1980 y ya para 1987 había descendido al 42\%, mientras las cintas de video pasaron del 1\% al 39\% (Augros, 2000; Rama, 2002).

Las antiguas salas perdieron rentabilidad. En la década del ochenta la exhibición cinematográfica en Montevideo aún se encontraba dominada por los grandes ámbitos céntricos sobrevivientes de la época de oro. Eran recintos inapropiados en tamaño y ubicación para la realidad del mercado, con salas enormes que no lograban abastecerse de las nuevas tecnologías ni contenían las prestaciones básicas adecuadas para el negocio. Ello condujo a la salida del mercado de muchos de los empresarios del sector de exhibición, que vendieron los cines. Al igual que en otros países de América Latina, las salas se convirtieron en estacionamientos, edificios de apartamentos, discotecas, supermercados o paseos de compras, en casos aislados terminaron en manos del Estado o como recintos vinculados a otras actividades culturales, y en su gran mayoría fueron comprados por grandes iglesias de última generación.

\section{Videoclubes y televisión por abonados}

En 1985, el mercado cinematográfico ya estaba frente al nuevo embate generado con la masiva irrupción de los clubes de video en todo el país, que produjo, siguiendo a Rama (2002), la desaparición de los viejos cines de barrio. En Uruguay, la expresión y el fenómeno de los cines de barrio, que tuvieron su apogeo durante la época de oro, refieren a aquellas salas que, a diferencia de las salas de estreno (por lo general céntricas), se ubicaron en otras zonas de la ciudad y servían de complemento del negocio. La oferta cinematográfica que brindaban (al igual que los videoclubes) era tanto o más variada que las de las salas de estreno, pero llegaban con posterioridad. Además, sus instalaciones eran más humildes y sus precios más populares.

Cuando la tecnología del video alcanzó a los consumidores a través del sistema de alquiler de películas, la calidad que ofrecían las salas cinematográficas no solo era pobre (debido a la decadencia antes reseñada de las salas y sus servicios), sino también costosa. Getino (1998) señala en Montevideo un aumento del precio promedio de las entradas de 1,2 dólares en 1985 a 5,5 en 1995. Esta es otra de las consecuencias que quizás expliquen la rápida expansión del negocio de videos domésticos. 
El mercado se desarrolló inicialmente mediante pequeños empresarios que ofrecieron el servicio instalándose en la mayoría de los barrios con modestos clubes de video (lo que podría asimilarlos a la vieja función que desarrollaban los cines de barrio) y más tarde a través de medianos o grandes emprendimientos insertos en centros comerciales, supermercados, y marginalmente en locales grandes e independientes instalados en zonas de alto nivel adquisitivo o con elevada concentración de posibles consumidores.

Paralelamente, entre 1989 y 1995, mediante sistema de abonados, se instalaron los sistemas de cable. Su llegada generó la idea de que, al depender menos de la publicidad - puesto que pasaba parte del costo a los usuarios-, a través de ella se obtendría una televisión más diversa (más temática y menos generalista) y, además del aumento de señales, una oferta de mejor calidad. Si bien estos hechos son relativos (el ejemplo más claro se encuentra en que la oferta de los diversos servicios difería muy poco), es indudable que las personas con capacidad económica adquirieron el servicio entendiendo que este les brindaba más cantidad y calidad de señales que la televisión abierta.

A medida que la cantidad de abonados comenzó a incrementarse en el último quinquenio del siglo XX, el sistema de videoclubes perdió importancia y comenzó también su declive - que levemente repuntó con la introducción del DVD, aunque volvió a entrar en crisis desde inicios del siglo XXI, con la mayor penetración de internet en la población- Así, luego de un período de auge a inicios de 1990, cuando en Uruguay había 900 videoclubes, la introducción de la televisión por abonados y la paralela reestructuración de las salas de cine hicieron que el negocio comenzara a decaer: eran unos 500 en 1995 y menos de 300 sobre fines de la década. Además, en su amplia mayoría experimentaron una baja del 40\% en los alquileres (Remedi, 2001; Stolovich et al., 2002; 2004).

\section{Llegada de los multicines}

A mediados de la década del noventa surgió un nuevo modelo de exhibición y explotación, mediante la incorporación de los denominados complejos de salas múltiples o multicines, que se tradujo en un resurgimiento de la concurrencia a salas de exhibición comercial o, en todo caso, un retorno - leve pero progresivo- del público a la gran pantalla. Así, en Montevideo, del punto más bajo registrado en 1994 (menos de un millón), se pasó a más de 2,5 millones de espectadores en el año 2000 (Observatorio Montevideo, s.f.).

Este nuevo modelo de exhibición, que llevó a la renovación del negocio, se basaba en complejos compuestos por varias salas pequeñas, con una amplia rotación de la oferta y una elevada calidad tecnológica de imagen y sonido. El esquema permitió racionalizar gastos y aumentar la rentabilidad del negocio (tanto para exhibidores como para 
distribuidores) mediante la centralización de actividades, menores gastos de personal y un mejor control de las recaudaciones.

Por otro lado, las fuentes de ingresos se diversificaron con productos anexos ofrecidos dentro de los complejos. Esto se observa claramente en Uruguay con la venta de palomitas de maíz y bebidas gaseosas, así como también con la posibilidad de explotar otros servicios, como la organización de eventos para empresas dentro de los complejos o incluso cumpleaños para grupos de particulares. Para el año 2000, ya en Estados Unidos el $40 \%$ de la facturación de los cines no provenía de la taquilla (venta de entradas), sino de la venta de productos alimenticios o de merchandising (Augros, 2000).

En América Latina, la desaparición de los viejos cines y la irrupción del nuevo modelo trajeron aparejado un desplazamiento dentro de la gestión, que pasó de manos de empresarios locales a una presencia dominante de los grupos trasnacionales con eje en los estudios (majors), a través de fuertes inversiones para controlar el mercado —algo similar a lo ocurrido durante la última etapa de la época de oro-. Así, por ejemplo, en países como Brasil y Argentina, con extensa producción y cultura cinematográfica, ya para 1999 el control de las multinacionales sobre el mercado de exhibición rondaba el $25 \%$. El caso de Chile es ilustrativo: hasta 1997 Conate-Chile (holding nacional) controlaba el $80 \%$ de las salas de exhibición y, tras la llegada de las transnacionales, para el 2000 solo poseía un 6\% del mercado. Por su parte, los grupos Cinemark, Hoyts y Showcase controlaban respectivamente el $42 \%$, el 38\% y el 14\% (Trejo Ojeda, 2000).

En Uruguay, entre fines del siglo XX y los primeros años del XXI, los grandes ámbitos dedicados a la exhibición cinematográfica en Montevideo se insertaron en centros comerciales de gran porte, lejanos de la zona céntrica de la capital (como los viejos palacios) y cercanos a las zonas costeras de mayor nivel adquisitivo, como los barrios de Carrasco (Portones Shopping), Pocitos (Montevideo Shopping) y Punta Carretas (Punta Carretas Shopping). De esta forma, el número de salas de estreno en la ciudad, que en 1991 era de 15 - 10 de las cuales estaban en la zona céntrica (Sanjurjo Toucon, 1992), llegó a 52 a mediados de 2001 (Schroeder y Lescano, 2002).

La cadena Movie Center -firma local, aunque réplica fiel de los ejemplos internacionales- se convirtió en la líder del mercado. La transnacional Hoyts (hoy Life Cinema) ingresó en Uruguay a mediados de los noventa, con instalación de complejos primero en Punta del Este y luego en Montevideo. Este panorama lo completó, siguiendo el mismo modelo, aunque con menor incidencia en el mercado, la cadena Grupo Cine. En 2002, estos emprendimientos, que acapararon el mercado regular de estrenos, vendieron más del 75\% del total de entradas, con menos del $45 \%$ de las localidades (Saratsola, 2005; Rama, 2002).

Por su parte, el mercado de la distribución en Uruguay se caracterizó por dos aspectos que continúan vigentes en la actualidad (véase Rey y Soria, 2015): 1) el mercado 
es muy reducido y 2) es uno de los pocos mercados donde distribuidores y exhibidores se encuentran, por lo general, fusionados.

Así, la única distribuidora de cine en sentido estricto era RBS, ya que no tenía salas de exhibición propias, salvo una en el barrio de Carrasco. A su vez, era la que tenía la mayor facturación dentro del rubro específico. Representaba localmente, para las ventanas de cine y video, a Buena Vista Internacional (Walt Disney, Touchstone, Miramax, Hollywood Pictures), United International Pictures (Universal, Paramount, United Artists, Dreamworks) e independientes argentinos. Posteriormente integraría un acuerdo con Grupo Cine (Remedi, 2003; Stolovich et al., 2004).

El resto de las grandes distribuidoras locales tenía vínculos estrechos con salas de exhibición cinematográfica. Hoyts representaba los contenidos de Twentieth Century Fox y contaba con un circuito propio de exhibición. Movie Center era representante local de Columbia Pictures-Tristar (Sony), Metro Goldwyn Mayer y otros sellos independientes; además, tenía un acuerdo de distribución en video con Censa. Grupo Cine representaba sellos independientes (en la actualidad tiene un acuerdo con RBS) y contaba con un circuito propio de exhibición (Remedi, 2003; Stolovich et al., 2004).

Por fuera de estos cuatro grandes, habría que mencionar a Dispel y ENEC. La primera también era una distribuidora en sentido estricto, ya que se dedicaba exclusivamente a la distribución del sello Warner Bros. ENEC, por su parte, representaba sellos independientes en cine y video y tenía una participación menor en la cadena de exhibición Hoyts.

\section{Consideraciones finales}

Partiendo de la llegada del cinematógrafo, se trazó un recorrido panorámico por el desarrollo de la distribución-exhibición cinematográfica en Uruguay, desde sus inicios hasta finales del siglo XX. El trabajo permitió identificar cuatro claras etapas en términos de periodización (primitiva, industrial, de divergencia y de reestructuración) que habilitan el desarrollo de futuras indagaciones en profundidad sobre el tema.

En un plano general, la primera etapa (1895-1920) fue un período primitivo del negocio. Hollywood prácticamente no existía. Las proyecciones se realizaban en lugares modestos y de escasas pretensiones, destinados a exhibir primero cortometrajes y luego películas de cine mudo acompañadas de música en vivo, a medida que se abrían salas específicas y el negocio de la distribución comenzaba a delimitarse. La empresa Natalini y Cía., creada en 1907, fue pionera en el país en el terreno de la distribución. En el campo de la exhibición, en 1910 Montevideo contaba con 30 salas y en 1920 la cifra ya llegaba a 63, en un proceso de ampliación que estallaría en las décadas posteriores. 
La etapa industrial (1930-1955) se caracterizó por ser un período de auge de la industria cinematográfica, con una estructura clara de producción, distribución y exhibición con eje en Estados Unidos que se denominó época de oro de Hollywood. Fue el momento de la llegada del cine sonoro, del cine de estudio y sus grandes estrellas, de la construcción y expansión de las grandes salas cinematográficas en todo el mundo. En Uruguay, la consolidación y expansión tuvo su más fiel representante en la empresa Glücksmann, que desarrolló su negocio a partir de grandes salas de exhibición y fundamentalmente a través de la distribución en exclusividad para el territorio uruguayo de las obras producidas por los estudios estadounidenses más importantes.

La tercera etapa (1955-1980) presenta un cambio de paradigma que se inicia con la llegada de la televisión. Hasta ese momento, el sistema económico cinematográfico se basaba en un principio fundamental: la recaudación se daba en salas. Se trató de un momento de crisis y de transformación del mercado a escala global, que observó un progresivo descenso de espectadores en las salas de estreno comercial mientras nacían y se desarrollaban otras formas de explotación que transformaban la industria. Este fenómeno de divergencia del mercado hizo que las enormes salas vieran sus ingresos fuertemente debilitados y, por consiguiente, comenzaran un proceso global de declive. En Uruguay este proceso fue acompañado por una crisis económica y social que desembocaría en un largo período de dictadura cívico-militar.

La última etapa (1980-2000) corresponde a la reestructuración del sistema de exhibición-distribución cinematográfico. En este período ocurrieron en Uruguay varios cambios que pueden condensarse en tres hitos: la llegada de los videoclubes, la televisión por abonados y el remplazo de las viejas salas por nuevos complejos de exhibición múltiples. Estos cambios se tradujeron en un mayor consumo de producciones cinematográficas que derivaron en una transición continua desde una forma de recepción colectiva del fenómeno hacia una más individual a partir de la creación de nuevas pantallas de circulación.

Resulta interesante preguntarse si los cambios procesados en el siglo XXI con el desarrollo de nuevas tecnologías a partir de la expansión de Internet y los dispositivos móviles (tabletas, ordenadores, teléfonos inteligentes), sumado a nuevas plataformas de distribución en línea (caso Netflix) o de difusión e intercambio (caso YouTube), plantean el inicio de una nueva etapa mediante la profundización de aspectos ya visibles de la etapa de reestructuración. Del mismo modo, resultaría pertinente indagar cómo estos cambios fueron procesados para el caso uruguayo. 


\section{Referencias}

Amieva, M. (2018). El Festival Internacional de Cine Documental y Experimental del SODRE: Las voces del documental y un espacio de encuentro para el cine latinoamericano y nacional. En G. Torello (ed.), Uruguay se filma: Prácticas documentales (1920-1990) (pp. 87-113). Montevideo: Irrupciones.

Augros, J. (2000). El dinero de Hollywood: Financiación, producción, distribución y nuevos mercados. Barcelona: Paidós.

Barbáchano, C. (1973). El cine, arte e industria. Barcelona: Salvat.

Barnow, E. (2005). El documental: Historia y estilos. Barcelona: Gedisa.

Bordwell, D., Staiger, J., y Thompson, K. (1997). El cine clásico de Hollywood: Estilo cinematográfico y modo de producción hasta 1960. Barcelona: Paidós.

Caetano, G., y Rilla, J. (2001). Quiebra del modelo (1955-1973). En G. Caetano y J. Rilla (eds.), Historia contemporánea del Uruguay (pp. 197-251). Montevideo: Fin de Siglo.

De los Santos Marauda, O. (1992). Cineclubismo: Pasado, presente y futuro de una forma de pensar. En C. Rama (coord.), Industrias culturales en Uruguay (pp. 217-230). Montevideo: Arca.

Dufuur, L. (2018). La Cinemateca del Tercer Mundo (Una cinemateca poco conocida). Toma Uno, 6(6), 27-40. Recuperado de https://revistas.unc.edu.ar/index.php/ toma1/article/view/20866.

Getino, 0. (1998). Cine y televisión en América Latina: Producción y mercados. Buenos Aires: Ciccus.

Gubern, R. (2016). Historia del cine. Barcelona: Anagrama.

Jacob, L. (1997). C3M: una experiencia singular (Trabajo de grado). Universidad ORT Uruguay, Montevideo.

Lipovetsky, G., y Serroy, J. (2009). La pantalla global: Cultura mediática y cine en la era hipermoderna. Barcelona: Anagrama.

Marchesi, A. (2001). El Uruguay inventado: La política audiovisual de la dictadura, reflexiones sobre su imaginario. Montevideo: Trilce.

Márquez, I. (2015). Una genealogía de la pantalla: Del cine al teléfono móvil. Barcelona: Anagrama.

Ministerio de Industrias y Trabajo. (1955). Cine en el Uruguay: Breve reseña histórica y guía general de salas de Montevideo e interior. Montevideo: MIT.

Observatorio Montevideo [Aplicación en línea]. (s.f.). Recuperado de http://www.montevideo.gub.uy/obmvd.

Radakovich, R. (2011). Retrato cultural: Montevideo entre cumbias, tambores y óperas. Montevideo: Licenciatura en Ciencias de la Comunicación. 
Rama, C. (2002). La globalización de la exhibición cinematográfica en América Latina. En E. Montiel (ed.), Hacia una mundialización humanista (pp.79-96). París: Unesco.

Remedi, G. (2001, 5 de octubre). El cine en casa. ¿Una historia condicionada y terminal? Brecha, pp. 12-13.

Remedi, G. (2003). Montevideo en sus pliegues: Mediaciones y mediadores en la ciudad. Revista Iberoamericana, 69(202), 65-84. Recuperado de https://revista-iberoamericana.pitt.edu/ojs/index.php/Iberoamericana/article/viewFile/5685/5832.

Rey, M., y Soria, F. (2015). La distribución de cine en Uruguay: Concentrado de película. Tercer Film, 3, 16-25.

Romaguera, J., y Alsina Thevenet, H. (1993). Textos y manifiestos del cine. Madrid: Cátedra.

Sanjurjo Toucon, Á. (2021). 125 años de cine en el Uruguay: 1896 - 18 de julio - 2021. Recuperado de http://accu.uy/index.php/2021/01/21/125-anos-de-cine-en-eluruguay-1896-18-de-julio-2021-alvaro-sanjurjo-toucon/.

Sanjurjo Toucon, Á. (1992). Las distribuidoras y el consumo de cine en Uruguay. En C. Rama (coord.), Industrias culturales en Uruguay (pp. 193-215). Montevideo: Arca. Sanjurjo Toucon, Á. (1994). Tiempo de imágenes. Montevideo: Arca.

Saratsola, 0. (2005). Función completa, por favor: Un siglo de cine en Montevideo. Montevideo: Trilce.

Schroeder, E., y Lescano, G. (2002). Programa de desarrollo de la industria audiovisual nacional. (Informe de consultoría). Montevideo, BID.

Stolovich, L., Lescano, G., y Mourelle, J. (1997). La cultura da trabajo: Entre la creación y el negocio. Economía y cultura en el Uruguay. Montevideo: Fin de Siglo.

Stolovich, L., Lescano, G., Mourelle, J., y Pessano, R. (2002). La cultura es capital: Entre la creación y el negocio: economía y cultura en el Uruguay. Montevideo: Fin de Siglo.

Stolovich, L., Lescano, G., Pessano, R., y Delgado, P. (2004). La industria audiovisual uruguaya: ¿realidad o ficción? Su impacto sobre las pymes. Montevideo: Ideas.

Trejo Ojeda, R. (2000). La industria audiovisual en Chile. Santiago: Ministerio de Educación.

Villaça, M. (2012). El cine y el avance autoritario en Uruguay: El «combativismo» de la Cinemateca del Tercer Mundo (1969-1973). Contemporánea, 3(3), 243-264. Recuperado de http://dialnet.unirioja.es/servlet/articulo?codigo=4245292. 